\title{
Line Managers' Perceptions of Diversity Management: Insights from a Social Exchange Theory Perspective
}

\begin{abstract}
Purpose: Drawing on Social Exchange Theory, this study explores line managers' perceptions of diversity management, as well as their perceptions of their role and responsibilities in shaping and implementing diversity practices. The senior management's leadership support, as it is perceived by line managers, in assisting them to manage diversity successfully, is also examined.
\end{abstract}

Design/methodology/approach: Semi-structured interviews with 51 line managers across different sectors in the UK were conducted in order to address the following three research questions. First, how do line managers perceive diversity management? Second, what are the actual roles and responsibilities of line managers in shaping diversity practices' implementation? Third, how do leadership interactions within the organisation influence line managers' perceptions of diversity practices?

Findings: Line managers present high levels of personal determination and commitment towards diversity supplemented by a consensus on the strategic role of leadership in relation to diversity management. In addition, poor levels of organisational support, leadership values and style are identified; all highly related to their ability to deliver results and, most importantly, to form effective relationships in the workplace.

Research limitations/implications: Data included line managers' views but not senior managers' perspectives, thus limiting the study in identifying the holistic impact of social exchanges in shaping effective relations. In addition, quantitative research could test and enhance the generalisability of existing findings.

Practical implications: Investing in social relationships can positively influence line managers' ability to deliver results. Action is required at organisational level by senior management to support and recognise line managers' critical roles in order to enable them to apply and promote diversity management.

Originality/value: These findings address a theoretical gap relating to the evaluation of the critical role played by line managers in the delivery of diversity practices. The study further demonstrates how social exchange relationships can influence line managers' perceptions of diversity management, an unexplored area within the diversity literature.

Keywords: Diversity management, line managers, leadership support, organisational support, Social Exchange theory 


\section{Introduction}

Diversity management (DM) has been defined as: "the specific programmes, policies and practices that organizations have developed and implemented to manage a diverse workforce effectively and to promote organizational equality" (Dennissen, Benschop and van den Brink, 2020:220). The term is premised on the recognition that successful DM leads to positive attributes within an organisation rather than resulting in problematic relationships that need to be solved (Thompson, 1997). Thus, DM has been represented as a 'morally praiseworthy' business need which requires organisations to develop appropriate Human Resource (HR) practices to support diversity goals (Greene and Kirton, 2011; Köllen, 2019; Olsen and Martins, 2012). The growing importance of decentralising HR practices to the line is further recognised as an important step to successful DM (Den Hartog, Boselie and Paauwe, 2004; Purcell and Hutchinson, 2007; Harney and Jordan, 2008; Brewster, Gollan and Wright, 2013). The main purpose of this study is to explore line managers' perceptions of DM as well as their perceptions of their roles and responsibilities in shaping and implementing diversity practices. In the past, significant contributions to literature in this field have focused largely on the importance of DM and its associated impact on individual employees and the organisation (Ashikali and Groeneveld, 2015; Ehrke et al., 2014; Richard, 2000). Extant literature does, however, tend to neglect the critical role played by line managers in the delivery of these diversity practices even though line managers have been recognised as: "... cornerstones in implementing diversity practices and conveying an organization's support for diversity and inclusion" (Ng, Sears and Arnold, 2020:unpaged). Arguably, this omission derives from a focus on organisational outcomes and performance indicators rather than on the relationship between line managers' perceptions of those practices and the approach they take towards implementing them in the workplace (Brewster et al., 2013; Boekhorst, 2015; Tomlinson and Schwabenland, 2010).

Wider organisational studies do provide useful context on related themes such as line management leadership style (Vermeeren, 2014; Purcell and Hutchinson, 2007), role stress (Evans, 2017) and HR policy adjustments (Boxall and Purcell, 2011). It is emphasised, however, that detailed analyses of the role played by line managers in the delivery of diversity practices are notable by their scarcity. This gap has led to clear calls for further research into this issue. For example, when reviewing literature on DM, Bleijenbergh, Peters and Poutsma (2010:420) conclude that: “...research is needed on how to increase managers' awareness of workplace diversity and support their involvement in the implementation process". Similarly, Ng and Sears (2020: 447) state that: "further research is needed exploring how line managers' beliefs and values contribute to the implementation and effectiveness of workplace diversity practices". In the light of calls of this nature, our study has two main objectives. The first objective is to explore line managers' perceptions of both DM and the influence of their role on the effective implementation of diversity practices. The second objective is to examine senior leadership's support, as perceived by line managers, in relation to DM. In order to address these objectives, the study draws on social exchange theory (SET) to provide insights into how social exchange relationships influence line managers' perceptions of diversity practices.

SET, as conceptualised by Blau (1964), centres on relationships which are based on trust and unspecified obligations. Notably, since this early conceptualisation, SET has been widely applied in organisational research with writers observing that mainstream theories of the psychological contract and organisational citizenship behaviour are "... firmly rooted in social exchange theory" (Tufan, De Witte and Wendt, 2019:2927). In complementary work on HR management (HRM), Ashikali and Groeneveld (2015: 758) 
state that: "... research on HRM outcomes has been based on social exchange theory which argues that the organization's and management's investments in HR practices and the organizational environment will elicit positive work attitudes and behaviour". Further, the authors postulate that, in the specific case of DM: "diversity management outcomes depend on the effect of employees' perceptions of diversity management on their attitudes and behaviour" (Ibid, 758). In our study, SET is utilised to examine line managers' perceptions of DM, as well as how their role and responsibilities of DM initiatives, alongside the organisational leadership and support provided, could influence the implementation of DM in organisations. We address calls to better understand how individual-level characteristics (e.g. managerial attitudes, beliefs, organisational relations) affect diversity management outcomes (Nishii et al., 2018). Thus, we give voice to line managers who are key contributors to the successful implementation and monitoring of diversity practices in the workplace. The paper is structured as follows. The first section analyses and evaluates key contributions from the academic literature on key dimensions of SET and the role of line managers in diversity practices, leading to the presentation of a set of research questions. The second section outlines the methodological aspects of the study and the third section details the empirical findings. The final section of the paper contains a discussion based on the research questions, followed by conclusions centred on our research objectives.

\section{Line Managers and Diversity Management}

It is widely acknowledged that poor understanding and interpretation of individual needs in organisations can lead to negative performance-related effects such as demotivation, turnover, absenteeism, and ineffective decision-making (Ashikali and Groeneveld, 2015; Ely, 2004; Martins, 2015; Shen et al., 2009). In the area of DM, Maxwell et al. (2001:479480 ) highlighted the role of line managers as "pivotal" while immediately recognising that: "... this category of staff is apparently under particular pressure in the organisational interpretation and application of managing diversity". Yet, despite the importance of garnering line managers' commitment to implementing organisational policies, it is unclear how social exchange interactions within the organisation can affect their ability to enact and implement diversity practices. As Foster and Harris (2005:14) state, the corollary of this lack of clarity about DM among line managers is that "... the architects of diversity policies need to take account of a range of contextual factors that impact of their delivery" and to adopt: "... a more contextually informed view of DM than is all too often suggested by the equality literature". This emphasis on social exchange and contextual interactions resonates strongly with prevalent themes of SET. Specifically, the following three research questions have been established to explore further key issues:

RQ1. How do line managers perceive DM?

RQ2. What are the roles and responsibilities of line managers in shaping diversity practices' implementation?

RQ3. How do leadership interactions within the organisation influence line managers' perceptions of diversity practices? 


\section{Social Exchange Theory}

SET highlights how strong social relationships, as represented in forms such as professional relationships, friendships, and organisational groupings, are critical to the creation of positive work attitudes and behaviours (Nishii et al., 2018; McClean and Collins, 2011; Nishii and Mayer, 2009; Gould-Williams, 2007; Aryee et al., 2002; Blau, 1964). In addition, SET outlines the importance of appropriate levels of organisational and leadership support, resource allocation and self-motivation to enable individuals to perform work-related responsibilities effectively (Martins, 2015; Purcell and Hutchinson, 2007). As such, this paper is based upon the premise that SET has the potential to provide insights into the role of social relationships in shaping line managers' perceptions of diversity practices. For example, SET highlights the importance of psychological and sociological exchanges that are necessary to form effective relationships including positive work attitudes and behaviours among individuals in organisations (McClean and Collins, 2011; Aryee et al., 2002). There is both theoretical and empirical agreement that line managers could effectively facilitate and enact HR policies and their delivery (Evans, 2017; Brewster et al., 2013; Hutchinson and Purcell, 2010). Therefore, examining line managers' understanding of DM (RQ1), and the level of their self-motivation, aims at shading light into how diversity practices could be enacted, shaped and implemented in organisations.

This enactment, however, requires effective employment relationships in order to maximise the benefits of diversity policies in relation to improved performance (Ashikali and Groeneveld, 2015; Dijk et al., 2012). SET is based on the premise that the social structure and dynamics of an organisation are highly informed by the roles and responsibilities of its members (Martins, 2015) by reciprocating with attitudes and behaviours that are beneficial for the organisation (Aryee et al., 2002). In line with that, and in relation to DM, examining how line managers' roles and responsibilities produce desirable outcomes and affected by social relationships (RQ2). Contextually oriented analyses, based on SET, further highlight the need to assess the role of leadership in shaping line managers mind-set in delivering results (Ugaddan and Park, 2017). On the one hand, literature suggests that organisational support is associated with shaping individual expectations and behaviours (Gigliotti et al., 2018; Wright and Nishii, 2013). For example, Grace (2013) and Tomlinson and Schwabenland (2010) argue that a diversity mind-set in the senior management group is essential for the successful implementation of any diversity strategy. On the other hand, a self-starting approach to work is also positively related to the level of environmental support, leadership group actions, corporate social responsibility (Bouraoui et al., 2019; Frese and Fay, 2001) and working conditions (Gould-Williams, 2007). With these in mind, examining how organisational and leadership support could influence line managers' perceptions of diversity practices, as well as their roles and responsibilities in relation to DM is essential (RQ3).

Earlier theoretical contributions revealed that individual attitude is important for establishing an appropriate social exchange climate, while it may also lead to the development of positive discretionary behaviours (Shapiro et al., 2011). For example, employees may respond to being valued and cared for by reciprocating with attitudes and behaviours that are beneficial to the organisation (Aryee et al., 2002). This lends support to the so-called 'HR attribution' as individuals' interpreted behaviour is influenced by management behaviour and employee welfare (Wright and Nishii, 2013; Lin and Lee, 2004) and lends further weight to the argument that the attitude of line managers and how they enact diversity practices is likely to be influenced by the level of organisational and leadership support provided to them. This argument finds support in the underlying premise of SET when described by Blau's (1964:91) as the: '... voluntary actions of actors that are motivated by the returns they are expected to elicit from others'. Yet, it is also evident from 
this premise that notions of poor leadership and leadership transgressions could have a detrimental effect upon individual behaviour including turnover and psychological withdrawal (Shapiro et al., 2011) and job performance (Harris et al., 2007). This observation is particularly relevant to the involvement of line managers in HR activities such as recruitment and selection and performance management. All in all, this study, through its research questions, aims at outlining whether strong social relationships, trust, and leadership support (SET), as perceived by line managers, are mutually benefiting (e.g. the organisation, the employees) in relation to DM.

\section{$D M$ and devolvement of $H R$ practices to line managers}

Several studies highlight the devolvement of HR practices to the line management (Alfes et al., 2013; Buller and McEvoy, 2012). Specifically, this devolvement of HR practices has resulted in line managers formally carrying responsibilities in the field of DM. In their critique of how line managers shape the impact of diversity practices aligned to HR policies, Buengeler et al. (2018: 290) cite research which has identified front-line managers as: “... critical drivers of the communication and implementation of HR practices: in their role as direct supervisor, leaders are important gatekeepers to the success of $H R$ practices". Similarly, Kirton and Green (2018: 70) state that: "line managers are also the ones who have the greatest influence on the equality and diversity workplace climate, which people experience on an everyday basis". In accordance with this premise, research on line managers' roles emphasises the need for positive relationships among leadership, organisational support and self-attitude towards work roles (Nishii et al., 2018; Avery, 2011; Nishii and Wright, 2008) and in-role performance (Farh et al., 2007).

Jayne and Dipboye (2004) and Ashikali and Groeneveld (2015) provide some useful perspectives by arguing that individual discretionary behaviour on diversity will vary due to the influence of various organisational practices and support such as performance and recognition. Equally, it is argued that poor 'dominant narratives' of knowledge could limit the ability of line managers to facilitate awareness, acceptance, adoption and adherence to diversity practices. This reinforces Ferdman and Brody's (1996) observation that change can only begin once awareness is acknowledged. Since attitudes are often imperfect predictors of individuals' actual behaviour it is tempting to believe that endorsement will translate directly into behavioural activism and/or disapproval into behavioural opposition, (Glasman and Albarracin, 2006). Furthermore, having organisations following an 'HR shared services' model, it automatically calls for line managers' involvement in the implementation of HR and DM initiatives (Ryu and Kim, 2015). Yet, the effective implementation of diversity practices cannot be guaranteed unless there is a clear understanding of DM. Thus, it is crucial to look at how line managers understand DM.

While the attitude of line managers may influence diversity endorsementinvolvement relationships via HR practices, the ability of line managers to deliver HR and diversity initiatives is disputed within the mainstream literature due to their extensive workloads, their lack of expertise in performing such accountabilities as well as owing to other work pressures (Nishii et al., 2018; Bainbridge, 2015; Op de Beeck et al., 2015; Gatenby et al., 2014; Watson et al., 2007). Nevertheless, line managers' involvement in HR and DM activities could also contribute to the development of their front-line employees under the broader aspect of organisational change and work relations (Gibb, 2011). Eventually, the successful fulfilment of line managers' diversity responsibilities may rely on their own sense of motivation and commitment to inform their respective subordinates (Vermeeren, 2014). As such, examining which roles and responsibilities line managers undertake in relation to DM is important. From a SET perspective, if a line 
manager demonstrates positive values towards policy implementation, this will help reciprocate attitudes and behaviours that are valued by the organisation (Van de Voorde $e t$ $a l ., 2012)$. Line managers should also be involved in decision making, regarding both HR and DM initiatives, owing to the information they could share as intermediates between senior management and front-line employees. More specifically, Tomlinson and Schwabenland (2010) strongly argue on the importance of leadership commitment and resource allocation towards diversity practices in non-for-profit organisations. However, their study is limited in relation to SET as it excludes how exchange relationships can affect line managers' perceptions of diversity practices; it raises questions as to how certain organisational realities could influence line managers' ability to support organisational diversity needs. Of course, contextual sensitivity is required to explore individual perception as the way line managers view their role and their experience of diversity practices can shape DM (Herdman and McMillan-Capehart, 2010). This view is consistent with managing diversity owing to the challenges arising from current demographic and social changes beyond other legal requirements (Tomlinson and Schwabenland, 2010). Therefore, it is essential to shed light as to how organisational leadership and support (SET) could influence line managers' perceptions to enact and implement diversity practices.

Social psychology literature suggests that contextual sensitivity can be achieved through the three components of attitude structure, namely, cognitive (that is, knowledge and understanding of individuals who are different), behavioural (that is, behaviours towards them and acceptance of their individuality) and affective (that is, involving emotions) components (Kirkpatrick and Kirkpatrick, 2006; Eagly and Chaiken, 1993). These components also feature as key competencies needed by line managers in relation to DM, for example, when establishing authentic relationships with individuals from different backgrounds (Hayles and Russel, 1997).

In summary, this study aims to provide an in-depth analysis of line managers' understanding of DM, firstly by examining their perceptions of their role and responsibilities in shaping and implementing diversity practices, and second by exploring whether their interactions with leadership figures influence their perceptions of DM. On the basis of the literature review, we argue that organisational contexts and realities which are established by social relations within an organisation could play a catalytic role in shaping line managers' mind-sets and their ability to shape and implement diversity practices. While the literature alludes to leadership and organisational support in setting individual expectations, there is a lack of knowledge as to how these realities might affect line managers' ability to diffuse diversity practices. Thus, we have sought to respond to this gap by means of a research design which involves a sample of line managers being offered the space to express their perceptions through the lens of SET.

\section{Research Methods}

In response to the research gap, the study adopted a qualitative methodology to bring forward the perceptions of line managers and to capture their context-specific understandings of organisational reality (Martins, 2015), specifically in relation to current diversity practices, and in line with the social exchange interactions in organisations. Due to the exploratory nature of the study, this approach was deemed appropriate to generate rich data, allow participants to share their perceptions in more depth (Paluck, 2006; Hayles, 1996) and capture emerging themes to address the research questions. This research study was designed to extend theory by adopting qualitative, interpretative methods and to offer an empirically led examination of the pivotal role of line managers in influencing DM practices. The adopted approach to this study enables the researchers to understand what is happening and why it is happening as understood by participants' themselves (Saunders, 
Lewis and Thornhill, 2009) and seek critical answers to questions through the application of a systematic, qualitative activities (Lune and Berg, 2017).

In total, 51 semi-structured interviews were conducted with line managers across different organisations in the U.K. (see Table 2). A purposive sampling strategy was adopted to select an appropriate number of participants (Miles et al., 2018). The scope was not to estimate a minimum sample size for the purpose of statistical generalisation, but to select participants that "fit with general constructs" (Curtis et al., 2000:1002). Although an important consideration was the diversity of respondents, and every effort was made to ensure that they reflected different sectors, the main priority of the study was to obtain the perceptions of line managers with an organisational responsibility for implementing diversity practices. This meant that the diversity of the sample was constrained by the composition of a population comprised of people occupying this role. Such an approach to sampling facilitated the rationale of replication relating to organisational size and type of sector and ensured exposure to different perspectives and experiences. The sample strategy was reinforced by the stage of data saturation. New themes stopped emerging after about 35 interviews, and an acceptable interpretative framework constructed after 45 interviews (see Table 1) (Lincoln and Guba, 1985). Reaching data saturation allowed the authors to assess individual perceptions and ensure the accuracy of the narrative about line managers' perceptions of diversity practices.

\section{Insert [Table 1 here]}

Our sample consists of 60 per cent female and 40 per cent male participants, with an age composition ranging from mid-thirties to late fifties, although the majority of respondents were in their thirties or earlier forties. All participants had direct responsibility for managing diversity activities at organisational level (at the point of the interview). Participants had a variety of different professional titles as organisations structure professional roles differently. To ensure that all participants satisfied the sampling requirements, their roles were verified with them both before and after the interviews. All participants were employed in the private sector in the UK. The vast majority were white British (85\%) with eight per cent (8\%) Black- British, and two per cent (2\%) Asian British, and the remaining five per cent $(5 \%)$ from other ethnicities. The vast majority of the participants held a university degree (62\%), with the rest (38\%) having another educational qualification such as a certificate, diploma, and/or professional body certificate). Table 2 provides a synthesis of the interview participants in detail.

Insert [Table 2 here]

Interview questions followed a semi-structured, retrospective approach to assess the way line managers have addressed problems over time as well as to examine their orientation to perceiving, believing and acting in a complex environment around diversity. To enhance the reliability of our research findings, interview themes were developed based on SET principles, further supported by Hayles' (1996) competencies in valuing diversity: head (Knowledge), hand (Behaviour and Skills) and heart (feelings and attitudes). In addition, participants were asked about their job role and supervisory responsibilities and working environment. This equivalence of questioning helped to standardise the semistructured interview and facilitate comparability (Paluck, 2006). Interviews were carried out outside participants' workplace to establish a 'bias free' environment and lasted for approximately 35 to 45 minutes.

Respondents were approached via an online email invitation outlining the purpose of the study and providing information about the need to hold diversity responsibilities. 
Access was sought after seeking ethical approval from various networks and professional bodies in the UK and receiving senior management consent to access their databases. The online invitation was accepted by 68 professionals who expressed a positive interest in taking part in the study. After verification of the sampling requirements, 51 respondents subsequently took part in the study.

Interviews were recorded, transcribed and analysed by adhering to the principles of 'thematic analysis' (Paluck, 2006) and the guidelines specified for constant comparison techniques (Glaser and Strauss, 1967). These techniques provided the basis for rigorous collection and clearly delineated themes and aggregated dimensions that emerged from the study (Miles and Huberman, 1994) as well as ideas and issues raised by the respondents. All data was grouped into key themes (open coding) and exposed to axial coding to explore relationships between those categories. These categories were further used to assemble higher-order themes (e.g. line managers' perception/self-motivation, role of organisational reality, leadership support and behaviour) for subsequent retrieval and exploration. Finally, all gathered themes were grouped into several overarching dimensions to allow the development of the study's emergent framework (Miles and Huberman, 1994). Throughout this process, key themes were compared with the literature to refine and strengthen the emerging interpretations. Table 3 provides key information about the second-order themes that emerged from the data analysis. Appendix 1 provides evidence of concepts derived from this analysis.

Insert [Table 3 here].

The generalisability of the findings is limited to the wider population of the respondents interviewed. Further to that, Miles and Huberman's (1994) tactics (for example, data reduction, data display, conclusion and verification) for generating meanings and testing relationships between themes throughout the process of analysing the data were also adopted to ensure the validity of the findings. All research participants were assured that the information they provided would remain confidential. Finally, the scope of the research was to present a detailed narrative of these dimensions by highlighting similarities and differences in what influences and forms their perceptions around social interactions and diversity practices from an individual perspective.

\section{Findings}

This section presents the major findings of this research. The first part evaluates how current social exchange interactions affect line managers' self-motivation to define and explain the importance of diversity at individual and organisational level. The second part focuses on how organisational and role realities influence line managers' ability to enact and implement diversity practices. This enables the authors to explore the actual vs the perceived role of line managers in supporting diversity goals. The third part provides an assessment of the role of leadership in shaping line managers' mind-set in delivering results. Findings are presented under those main themes as highlighted in Table 3 further using appropriate verbatim quotes from most participants to illustrate those findings.

\section{How do line managers perceive diversity?}

To address the first research question, line managers (LMs) were asked what diversity in the workplace means to them. All participants had significant experience and knowledge of diversity, as well as a responsibility for the design and implementation of diversity practices at organisational level. Interestingly, line managers' attitude towards diversity 
practices have been documented in the interviews with particular reference to "personal initiative'. This was a strong theme emerged from the interviews highlighting the role of self-motivation to DM $(n=38)$. It demonstrates the need to engage individuals with DM:

"I am very committed... it is about bringing different kinds of people from different backgrounds together and it is having knowledge on DM in organisations from different areas" (LM3).

In relation to the question on what induced line managers to highlight the role of personal initiative, participants mentioned personal commitment to promote diversity and generally support organisational diversity needs. More frequently, they referred to personal knowledge and commitment to highlight the benefits of diversity at individual and organisational level and, in many cases, the ability to change individual attitudes towards diversity and equality. Participants highlighted that diversity could be potentially a positive tool with one of them arguing that:

"[...] we are more diverse as a nation, more diverse as an industry, a diverse customer base, inclusive working environment and you need to raise awareness, address religion and cultural differences" (LM26).

While the attitude of participants towards their diversity roles partly explains the eagerness of their current organisational roles, personal initiative results in participants taking an active and self-starting approach to personal commitment on diversity. When describing their motivations behind diversity there was a high level of personal determination to highlight the need to change perceptions around diversity and its role in supporting organisational goals. Most participants expressed their determination towards diversity by arguing:

"We live in a highly diverse society so we must take actions to represent communities and enable organisations...you know...to prepare themselves" (LM28).

They recognised that organisations now operate in a highly diverse and complex business environment. Therefore, actions should be taken to raise awareness about how to address strategic and operational diversity needs. As one of the participants explained:

"[...] diversity is about having a range of people and a range of backgrounds involved in an organisation which represents the culture that we work within" (LM13).

Another participant highlighted that:

"There is not another way... if the same kind of group works for you, no chance to innovate and change. You need diverse skills. Diversity is the only way forward...definitely promote diversity. It is important to take positive action should a bias emerge that might suggest a monoculture does not work" (LM22).

It was also acknowledged that participants perceive diversity as a natural organisational activity as all individuals deserve respect in the workplace through a healthy working environment. This demonstrates a strong knowledge base emerged from their own desire to address daily diversity issues and challenges. Further questioning how organisations 
approach diversity needs, the element of organisational imperatives and strategic fit were extensively highlighted. Findings demonstrated that any prior positive self-motivation about diversity has been negatively changed due to a number of organisational realities including the ability to utilise personal commitment in an attempt to support organisational diversity needs. For example, the vast majority of participants $(n=48)$ mentioned how the adoption of their personal knowledge was not coherent with 'organisational realities' and with the core leadership 'values'. As such, they argued it was their 'duty' to adopt their style to address organisational needs with particular emphasis on compliance with legal requirements. For instance, a line manager argued:

"I have to make feasible decisions related to the current legislation" (LM32).

Most participants described the decision to adopt their personal initiative to organisational realities as a 'compliance' act to maintain employment and achieve workrelated goals, by arguing:

"It is like cherry picking and being selective with how to address diversity issues which is just the legislation" (LM6).

They frequently commented on a level of frustration and 'guiltiness' as they were 'apologetic' in their response on how they justified their personal knowledge and initiative within their current organisational roles $(n=46)$. Such a behavioural attribute was a strong dimension in the interviews demonstrating the important role of personal accountability to manage organisational expectations with DM outcomes. A representative comment around this argument is:

"Legislation has to be there, some companies do not bother, just legally comply, but the framework should be adopted at individual level. I do try... but certainly it is the law framework [...] not flexible to create an un-bias policy, which is less regulatory" (LM1).

Although these negative comments were common amongst participants, they were rarely voiced at organisational level. Participants' responses to address current legislative requirements were deemed as a 'necessity'. In addition, these were seen as a frustration emerged due to a lack of emotional engagement and personal knowledge utilisation to actually support diversity strategies or, as they view it, 'to have a positive impact on the organisation' (LM51). Failure to utilise self-motivation and commitment seems to act as a barrier to inform and articulate diversity issues in the workplace. Uniquely, they argued that personal knowledge is mainly utilised by organisations to address operational targets rather than to support the implementation of specific diversity goals. This might not come as a surprise, however, findings strongly suggest that leadership commitment to support line managers as yet to feature as an espoused part of DM implementation. A representative statement is:

"We do not have any specific policy and recruitment is a very structured with no training or emphasis on diversity, there is no time to actually go beyond the legal perspective...target, pressure and target again and again... "(LM50).

Another participant mentioned that:

"Think about organisational reality and then make any decision by using my personal values and reputation. People do not actually understand the importance 
of diversity. It is because either they are fearful of talking about it or they lack knowledge and understanding. Even if the organisation offers training, managers are not particular willing to challenge themselves" (LM33).

\section{Roles and responsibilities of line managers in shaping diversity practices' implementation}

Evaluation of the findings also suggests that organisational pressures in satisfying key competencies and delivering results limit personal commitment for developing individual knowledge. Urgency to delivery results with unrealistic expectations affects line managers to identify and assess which policies and practices are most effective at building the capacity to achieve DM goals $(n=48)$. However, the sense of duty to shape diversity practices is not signalled by positive organisational response. One participant highlighted:

"I also have to approach management carefully and have a balanced approach assessing the pros and cons, and then decide what to do and how to do it, the least you want is to upset the management with your actions" (LM4).

Further questioning it was revealed that organisational approaches to learning and development might not be in line with personal levels of commitment amongst line managers. The importance of learning has been highlighted by one line manager as a response to DM due to high levels of personal and organisational engagement with learning. In her own words,

"Acknowledging people have differences is key...have to be open...accessibility is everything. Openness is key in everything we do [...] performance review use diversity as one of the key values; it is working as people have been asked questions on how they appreciate differences" (LM9).

This shows a high level of professional desire to affect organisational reality. Few participants presented a positive perspective about the current organisational realities highlighting high level of recognition. They argued that openness, consistency and valuing knowledge assist their role in implementing diversity strategies. For example, it was stated that:

"We have core competences and goals but supervisors do not have a say into how they recruit or manage difference. There is a need for more flexibility to provide opportunities to express ideas" (LM19).

Another participant noted:

"I believe trust, having trustworthiness, you know, in relationships within the organisation is very important. Without trust people would not appreciate your contribution to the organisation and, most importantly, wouldn't allow you to make necessary changes" (LM49).

The level of organisational support and appropriate utilisation of current resources was seen as a key barrier to support their role in promoting diversity. Looking beyond initial comments, participants' current endorsement towards diversity is limited towards 
addressing work commitments with less emphasis on taking obligatory actions, with a line manager suggesting:

"I just go to do my job, and that's it... do as I'm told" (LM46).

Adhering to the company's diversity practices seems to generate role ambiguity as they argued that they are unlikely to maximise personal outcomes which could put them either at odds with, or in favour of, diversity due to the nature of organisational support. Participants emphasised the vagueness of current nature of their roles in the workplace and highlighted the need to remove biases from the workplace by arguing that:

"...having the support as a background is very good...support is everything, it builds confidence and provides room to improve practices but this depends on the acceptability level at management level... the more flexible the better... but currently you always have to be careful how you express concerns and avoid saying you need to do this and need to do that" (LM27).

However, they did not provide a clear justification on the meaning of bias although they argued that poor organisational support dismisses individual commitment and contribution to satisfy diversity practice expectations. The vast majority $(n=42)$ argued that they felt less confident in achieving work-related expectations as part of their role due to financial and resource restrictions. Their frustration has been widely expressed throughout the interview. For example, one participant suggested:

"Leaders are open to listen to ideas, listen to what we have to say, they are listening to how problems can be resolved, but always political correctness and resource implications prevent those change to be fully implemented" (LM8).

Findings strongly suggest that resource implications and financial pressures create a level of ambiguity towards line managers' ability to undertake their duties. In part, resources are available to support the implementation of operational diversity activities:

"...but how we use that is a different story...it is upon them to use those resources, there is a pressure to effectively utilise resources though. You need to make sure decisions are effective and cost effective" (LM12).

Participants' efforts to disseminate their positive 'personal initiative' were dismissed by the lack of clear objectives and responsibilities to progress diversity initiatives. More specifically, more than half of participants $(n=34)$ argued that there is lack of support in undertaking their role. This is an interesting finding as organisational cognitive and behaviours and, how roles and responsibilities are defined in the workplace directly affects their efforts to implement DM practices. For example, a representative statement is:

"No support at all. There is not a clear understanding on how and what to do" (LM10).

One participant mentioned that ideas or strategies could not be implemented due to staff shortages:

"I am on my own and this creates a number of positive outcomes but at the same time negative ones. The positive one is I can respond quickly to different issues and 
people do value my knowledge and my opinion because can give them concrete solutions. The negative of that is you work on your own, you cannot really see what needs to be done and do not have the time to do as much as I want” (LM25).

Another line manager stated that:

"Whenever people have raised ideas and there is a cost element, management always say things like, okay thank you for that, we will look into it [...] they are aware of the needs, but cost is always an issue that they take into account" (LM43).

On the contrary, there were a few positive responses $(n=3)$ concerning the level of organisational support. For example, a participant stated that she feels confident to request appropriate resources, stating that:

"The company itself has a good reporting structure. I think that the management's openness and transparency in the process does make a difference as you know exactly what to do and how" (LM31).

Nevertheless, financial pressures and individual ignorance have brought to the surface participants' 'fear' about the future and their role in contributing towards diversity success. Concerns have been raised about current labour market trends and approaches to training, with most participants $(n=48)$ arguing that more flexibility and resources are needed to act strategically in such an uncertain environment. This was a strong feature in the interviews as absence of pro-diversity behaviour and perceptions affects the relationship between line managers' attitude and their ability to change the organisational agenda on DM. Organisational realities certainly determine participants' mind-set on DM in the workplace. For example, one of the participants argued that:

"Many business models often suggest that a standardised approach to a set problem is the most efficient way to deal with it. Standardisation is easier to achieve in a monoculture, but it does not provide any scope for flexibility in a nonmonoculture organisation" (LM39).

\section{The influence of leadership interactions on line managers' perceptions of diversity practices}

The dominant theme that emerged from the findings demonstrates a lack of clarity and individual accountability amongst leaders. This ambiguity was expressed in a format of personal 'confession' through the interviews. Their confession highlights all the feelings expressed in the interviews from guilt to frustration, and desire to apathy. Most importantly, participants' confession highlighted concerns about current leadership support, arguing that leaders are unaware of the implications of poor diverse workforces. As one of the participants recalled:

"I would say that it is poor. While the rhetoric is sound there is little tangible promotion of diversity, particularly amongst its workforce. Whilst our organisation is described as a good employer generally in terms of caring for its workforce the way in which it promotes itself and the way in which it looks do not match (senior staff for instance)" (LM2).

Assessing participants' mind-set, our findings indicate that leadership style directly affects their level of commitment, and most importantly their ability to use personal 
initiative. A number of participants $(n=35)$ argued that diversity is not a key organisational priority, thus highly questioned leadership commitment towards addressing diversity objectives to support this. As one of the participants said it is just a cover up, a nice cover without any substance, poor very poor' (LM18). The following statement summarises participants' perceptions:

"Little emphasis or interest at the highest level to change the way we do things. It is hard to talk about this... we are not deaf [...] management is a bit hesitant to actually listen but you need to achieve operational goals and effectively manage effectively expectations... a lot of staff members including leaders, are not as cooperative with filing in forms and therefore will be unclear of what the policy entails exactly. I do not agree but I have to follow with the decisions though" (LM7).

While uncertain as to the leadership role in diversity, participants were reluctant to place their voice as they argued that old-school management and leadership styles hinder organisational progress in diversity and equality. Looking beyond initial, leadership beliefs and perceptive on DM certainly affects the interaction between strategic implementation and delivery of diversity goals. Interestingly, most participants $(n=35)$ found this relationship difficult to manage within their current roles. For example, one highlighted:

"They have been around for a long time, they are just limited with what they look for and they are narrow-minded. Mid-managers might have the passion but leaders are not encouraged to change, no cultural shift and not open to new ideas" (LM16).

Regardless of the evidence, participants were aware of the wider organisational dynamics. They were able to explain and balance organisational expectations, ultimately leading to the implementation of diversity practices that satisfies specific organisational needs. Whether these needs are away from the principles of DM or not is a secondary element. A primary element emerged from the finding is the values of such a relationship. This was strongly evident in the interviews when they expressed their frustration about current leadership attitude and their inability to establish effective relations based on trust and unspecified obligations. This could offer an indication that line managers' frustration was largely driven by the lack of recognition of being key facilitators to provide organisational support. Respectively, this left them unsure about the level of leadership support by arguing that:

"I'm sort of like the middle link and sometimes I feel that probably they're a bit, how can I put it, not as understanding if you like as I am" (LM18).

In other words, participants' perceptions were negatively affected by leaders' actions at work and their attitude towards workplace norms and support. The level of support was well highlighted in the interviews as they believed that individual leaders' commitment to diversity could influence the effectiveness of their role. As one participant remarked:

“...resistance is what I think is a major barrier, leaders not taking it seriously. I think this is partly due to lack of communication and disorganisation [...] some leaders do not actually bother, it is too much of a risk ... not top on their agenda... I don't know, it is something that you simply accept" (LM37). 
The following statement is also a powerful expression of participants' perceptions of current leadership behaviour:

"Less accepting of people being different and less committed to actually put into practice various strategies is dangerous. Leaders might not be approachable and this can cause issues in terms of people perception. However, I believe leadership attitudes to diversity is key, you have to put forward ideas and express concerns; they might be rejected but ideas should be considered. Nevertheless, this is definitely not always the case" (LM21).

Others $(n=28)$ argued that some leaders are knowledgeable and aware of current equality and diversity issues but there were a few participants $(n=8)$ who further suggested that their leaders 'don't have a clue' (LM34). This might not be of a surprise as organisations approach diversity differently based on their business strategy. Nevertheless, it seems that the level of leadership knowledge on both operational and strategic aspects of managing diversity is a crucial factor in managing expectations. This has been highlighted in the form of organisational priorities, as one mentioned:

"...diversity is not often on the agenda...they are not focused on diversity, you know. There are many financial pressures currently, a lot of pressure to achieve our general objectives and our priorities. I think the assumption is, well we are not terrible at that and I do not think we are terrible at that, so it just will not...I think it would be difficult to make it more of a priority" (LM2O).

Few participants $(n=3)$ were more positive and sympathetic towards leadership support. They argued that they feel confident to hold discussions with senior leaders to address diversity issues on a regular basis. They recognised that there are some clear goals and it is a top-down tool as the organisation itself embraces diversity in all different aspects. For example, one of the participants argued that:

"Two years ago, we were acquired by a large organisation. I think that straight after, diversity came up on the agenda.... Having to work with people across different cultures resulted in enhancing our diversity understanding, further informing the ways of working within the new corporation" (LM23).

They further commented that effective organisational culture has the potential to influence individual committee and this is critical to enable leaders to take more ownership of diversity and thus to put less pressure on HR practitioners.

\section{Discussion}

Although diversity is a complex topic, our findings strongly outline the effective engagement of line managers as a key stakeholder of setting and achieving diversity goals; this could also prove as a critical success factor for organisations to move forward the diversity agenda. The findings extend the link between SET and diversity literature by justifying a key theoretical proposition that effective social exchange relationships, trust and organisational leadership and support could affect line managers' ability to address diversity needs at organisational level (i.e. Ng, Sears and Arnold, 2020; Dennissen, Benschop and van den Brink, 2020; Bleijenbergh, Peters and Poutsma, 2010). As such, our findings offer empirical support for the relevance of Ashikali and Groeneveld's (2015) 
argument on the importance of social interactions in relation to HRM outcomes, and more specifically to the specific area of DM.

In addressing the first research question, our findings provide insights into line managers' perceptions of DM, as well as of the ways in which organisations might fail to create a 'healthy' social environment where knowledge around diversity and equality could be shared and utilised. These insights are noteworthy given the influence of line managers in DM (Kirton and Green, 2018) and the need to address organisational issues related to diversity and equality ( $\mathrm{Ng}$, Sears and Arnold, 2020). In our study, the line managers' narratives paint a very bleak picture of how organisations attempt to address diversity needs by utilising their knowledge and commitment to DM goals. This is an added contribution to the literature as the study strongly supports the argument that high levels of personal initiative to managing diversity and to communicating personal ideas are critical to line managers' ability to deliver and support effective diversity outcomes. Line managers' individual knowledge about diversity also reciprocates positive attitudes and behaviours. This is essential, with our study confirming key recommendations that cognitive, behavioural and affective knowledge elicit positive work attitudes and emotions (Kirkpatrick and Kirkpatrick, 2006). The added value is that line managers' self-motivation appears to be fuelled predominately by their own desire to utilise individual knowledge to contribute towards the diversity agenda at organisational level. This ambiguity was primarily caused by a lack of resources and poor utilisation of personal knowledge in decision-making processes, thus resulting in low-quality social relationships. This was attributed to line managers' behavioural changes which were manifested by less passive and implicit behaviours at the organisational level. Thus, at the individual level, line managers displayed more positive and explicit attitudes towards supporting the diversity agenda and were actively engaged in behaviours exemplifying this support. They simply make decisions by consciously reassessing the nature and quality of their relationship with organisational realities.

The second research question explored the roles and responsibilities of line managers in shaping diversity practices' implementation. Our findings shed light on the relationship that exists between line managers' self-motivation and the need to address organisational obligations. Specifically, in relation to the role of line managers in DM, our findings confirm the relevance of social exchange studies which highlighted the influential role of individual attitudes to the development of positive discretionary behaviours (Shapiro et al., 2011). In addition, our findings outline that line managers could be the 'victims' of their own knowledge for promoting diversity. The more knowledgeable they are around DM, the easier its implementation would be and vice versa. This is a significant contribution to the literature as our findings strongly support that organisational realities could limit line managers' ability to achieve organisational diversity goals. The study demonstrates that lack of organisational clarity on DM strategy directly affects the quality of the established relationships between line managers and leaders. This indicates the strong necessity for organisations to create the space and structure for line managers to utilise their roles and responsibilities in an attempt to support the designing and implementation of DM practices.

The third research question examines how leadership interactions within the organisation can influence line managers' perceptions of diversity practices. Our findings, in line with the findings of previous studies (Grace, 2013; Tomlinson and Schwabenland, 2010; Wright and Nishii, 2013), highlight leadership commitment as a primary factor in determining line managers' ability to undertake diversity responsibilities; thus, our findings provide further evidence that leaders' role-making in relation to their strategic responsibility has a direct effect upon line managers' ability to contribute towards the diversity agenda. The new insight here is the fact that poor level of commitment and sense 
of 'apathy' among leaders reciprocate line managers' negative attitudes and behaviours towards the realities in implementing diversity practices, and eventually the outcome of diversity practices. Our findings extend current debates by arguing that leadership style could create a feeling of role ambiguity which directly influences line managers' sense of contribution in undertaking their duties and responsibilities. This role ambiguity has implications both for DM and subsequent job satisfaction, job performance, training and leadership (Alshery et al., 2015; Al-Malki and Wang, 2003) leading to poor DM outcomes. As SET theory highlights, effective relationships are two-sided, mutually contingent and mutually rewarding involving effective exchanges (Blau, 1964). The study shows that current relationships are mostly based on two narrow perspectives: costs vs benefits. It is clear that cost subtracts the benefits of DM leading to poor social behaviours. Line managers have a series of interactions in the workplace that generates obligation (Emerson, 1976). Important for this study is that such obligation leads to behaviours and expectations that are less effective to lead the DM agenda. There is no doubt that organisations need to weigh the potential benefits and risks of any strategy. However, when the risks outweigh the rewards, this creates a high level of withdrawal amongst line managers. Such implicit behaviours could damage any attempt to address future DM needs and create a more effective workplace for all employees.

From a critical perspective, our study strongly demonstrates that line managers' perceptions are affected by poor levels of organisational support and the lack of capacity to create a positive organisational momentum for real change. Organisational support is related to 'freedom', structure and clarity on how diversity issues are discussed and addressed in the workplace. Line managers' narratives indicate a high level of frustration about the poor commitment to supply resources due to financial pressures. Yet, our findings suggest two common organisational realities that add value to the literature. First, organisational financial resources determine the level of priority around diversity needs. Second, a lack of resources contributes towards the creation of a culture of apathy and silence amongst line managers. Eventually, our study extends current evidence that organisational realities reinforce a high level of psychological withdrawal for building those effective social relations required to support achieving diversity goals. This represents a detrimental behavioural reaction emerging from the lack of constructive social engagement in the workplace. Poor organisational support neither promotes positive exchange relationships between line managers and leaders, nor line managers' belief that their efforts are being recognised and supported. The novelty here is that line managers strongly highlighted the need to develop quality, further confirming the point that 'each must see the social exchange as reasonably equitable and fair in order to continue it' (Graen and Scandura, 1987, p.182). Appropriate levels of organisational support are likely to help line managers' efforts towards helping to achieve diversity goals, but most importantly to establish behaviours needed to address future diversity needs. Relevant reports further emphasise on the importance of setting clear diversity priorities (e.g. gender-diverse teams, inclusive teams) and continuously monitoring their progress in relation to employee outperformance (Hunt et al., 2015; Deloitte, 2013; Catalyst, 2004). Therefore, our study reinforces the need for real change on how we define, organise and manage diversity needs at organisational level. This is alarming evidence as DM is based on the need for organisational actions and proactive efforts to manage their diversity (Greene and Kirton, 2011).

Consequently, our study satisfies calls to explore further the critical role of line managers in the delivery of diversity agendas, thus confirming a number of arguments in the role as to what could influence their intention to enact diversity practices $(\mathrm{Ng}$, Sears and Arnold, 2020; Boekhorst, 2015; Brewster et al., 2013). Notably, in their research, Dijk et al. (2012) found that the establishment of effective diversity initiatives is essential to the 
development of positive employment relationships. Our findings emphasise that positive social exchanges are required to form effective relationships between line managers and leaders, thus confirming the view that line managers' efforts to enact diversity practice are influenced by senior management behaviour (Ashikali and Groeneveld, 2015; Shapiro et al., 2011). Hence, it is essential to re-access how the diversity agenda is structured, delivered, and socially maintained at the organisational level in order to create the infrastructure for line managers to share knowledge when implementing policy and making decisions about DM.

\section{Conclusion}

The two main objectives of this study are first, to explore line managers' perceptions of both DM and the influence of their role on the effective implementation of diversity practices, and second, to examine senior leadership's support, as perceived by line managers, in relation to DM. In relation to these objectives, the findings lead us to conclude that, while line managers may be aware of diversity issues and their positive implications, the potentially positive effects associated with these attitudes are likely to be hindered by vague and inadequate behaviours of senior leaders. Hence, the role of line managers in DM may rightly be described using terms such as 'critical', 'critically influential' and 'pivotal' (Buengeler et al., 2018; Kirton and Green, 2018; Maxwell et al., 2001); however, our findings emphasise that it is important to recognise intervening and confounding variables, such as senior leadership support and resource availability, when seeking to assess the relationship between line managers' behaviours and the outcomes of DM initiatives. Without positive organisational environment, diversity goals will simply address legal obligations and fail to create the space for line mangers to create positive experience for individuals in the workplace.

At a general level, this study highlights that line managers' low self-motivation can harm the advancement of the diversity agenda in the future. This particular conclusion reflects what has been highlighted in past studies on the role of organisational realities in shaping expectations (Emerson, 1976; Frese and Fay, 2001). We acknowledge that internal and external environmental changes may influence the design of any strategy. However, by emphasising the value of SET, this study strongly suggests that investing in social relationships can positively influence line managers' ability to deliver results. It is acknowledged that HR policy could influence individual levels of self-motivation (Wright and Nishii, 2013; Purcell and Hutchinson, 2007), but organisational support and recognition appear to be key success factors to generate desired behaviour amongst line managers. This requires actions by senior management to alter and manage negative behaviours through informed investments in training and development and through finding ways to enhance work relations between different levels of management.

The findings provide a foundation to support future research designed to investigate aspects of diversity and social exchange research from a mixed methods perspective. It is important to develop robust, empirically driven studies to gauge the effect of leadership and power on line managers' attitudes towards diversity as well as to further evaluate the extent to which high levels of self-motivation could act as an 'agent of change' in supporting diversity goals. This confirms Bowen and Ostroff's (2004) suggestion that individual perceptions of HRs practice is dependent on management behaviour through the means of effective levels of commitment. Nevertheless, this study has the potential to engender greater impact upon diversity practices to enable line managers to better perform their critical duties in supporting diversity goals. Such actions could be informed by these insightful findings on how line managers behave towards current organisational diversity practices. 
Finally, the study has a number of limitations which need to be highlighted. First, the study was carried out with a limited number of individuals across different sectors due to its qualitative nature. Second, data were collected only from line managers and not senior managers thereby limiting the ability to identify the impact of social exchanges in shaping effective relations. In recognising these limitations, we posit that future research would benefit by the inclusion of senior managers in examining their perspectives and comparing them with those of line managers.

\section{References}

Alfes, K., Truss, C., Soane, E.C., Rees, C. and Gatenby, M. (2013), “The relationship between line manager behavior, perceived HRM Practices, and individual performance: Examining the mediating role of engagement", HR Management - Special Issue: HR Management and the Line, Vol. 52 Issue 6, pp. 839-859.

Al-Malki, M. and Wang, J. (2003), "Impact of Laissez-faire leadership on role ambiguity and role conflict: implications for job performance", International Journal of Innovation and Economic Development, Vol. 4 Issue 1, pp. 29-43

Alshery W.B.R., Ahmad, F.B. and Al-Swidi, A.K. (2017), "The Moderating effect of role ambiguity on the relationship of job satisfaction, training and leadership with employee performance", International Journal of Business Administration, Vol. 6 No. 2, pp. 30-41.

Aryee, S., Budhwar, P.S. and Chen, Z.X. (2002), "Trust as a mediator of the relationship between organizational justice and work outcomes: Test of a social exchange model", Journal of Organizational Behavior, Vol. 23 Issue 3, pp. 267-285.

Ashikali, T. and Groeneveld, S. (2015), "DM in public organizations and its effect on employees' affective commitment: the role of transformational leadership and the inclusiveness of the organizational culture", Review of Public Personnel Administration, Vol. 35 Issue 2, pp. 146-168.

Avery, D.R. (2011), "Support for diversity in organizations: a theoretical exploration of its origins and offshoots", Organizational Psychology Review, Vol. 1 Issue 3, pp. 239-256.

Bainbridge, H. (2015), "Devolving people management to the line: How different rationales for devolution influence people management effectiveness", Personnel Review, Vol. 44 No. 6, pp. 847-865.

Blau, P. (1964), Power and exchange in social life, John Wiley and Sons, New York.

Bleijenbergh, I., Peters, P. and Poutsma, E. (2010), "DM beyond the business case”, Equality, Diversity and Inclusion, Vol. 29 No. 5, pp. 413-421.

Boekhorst, J.A. (2015), "The role of authentic leadership in fostering workplace inclusion: A social information processing perspective", HR Management, Vol. 54 Issue 2, pp. 241264.

Bouraoui, K., Bensemmane, S., Ohana, M. and Russo, M. (2019). "Corporate social responsibility and employees' affective commitment: A multiple mediation model", Management Decision, Vol. 57 Issue 1, pp. 152-167. 
Bowen, D.E. and Ostroff, C. (2004), "Understanding HRM-firm performance linkages: The role of "strength" of the HRM system", Academy of Management Review, Vol. 29 No. 2, pp. 203-221.

Boxall, P. and Purcell, J. (2011), Strategy and HR management, Palgrave Macmillan, Basingstoke.

Brewster, C., Gollan, P.J. and Wright, P.M. (2013), "Guest Editors' Note: HR Management and the Line”, HR Management, Vol. 52 Issue 6, pp. 829-838.

Buller, F.P. and McEvoy, M.G. (2012), "Strategy, HR management and performance: Sharpening line of sight”, HR Management Review, Vol. 22 Issue 1, pp. 43-56.

Catalyst, (2004), The Bottom Line: Connecting Corporate Performance and Gender Diversity, A report retrieved from the Catalyst Organisation, available at: https://www.catalyst.org/research/the-bottom-line-connecting-corporate-performanceand-gender-diversity-japanese-version/ [Assessed $14^{\text {th }}$ September 2019].

Deloitte, (2013), Waiter is that inclusion in my soup? A new recipe to improve business performance, A research report prepared by Deloitte (May 2013), retrieved from Deloitte website, available at: https://www2.deloitte.com/content/dam/Deloitte/au/Documents/human-capital/deloitteau-hc-diversity-inclusion-soup-0513.pdf [Assessed 10 ${ }^{\text {th }}$ October 2019].

Den Hartog, D.N., Boselie, P. and Paauwe, J. (2004), "Performance management: a model and research agenda", Applied Psychology: An International Review, Vol. 53 Issue 4, pp. 556-569.

Dennissen, M., Benschop, Y., and van den Brink, M. (2020), "Rethinking DM: An intersectional analysis of diversity networks", Organization Studies, Vol. 41 No. 2, pp. 219-240.

Dijk, H., Engen, M. and Paauwe, J. (2012), "Reframing the Business Case: A values and virtues perspective", Journal of Business Ethics, Vol. 111 Issue 1, pp. 73-84.

Eagly, A.H. and Chaiken, S. (1993), "The psychology of attitudes”. New York: Harcourt, Brace, Jovanovich.

Ehrke, F., Berthold, A. and Steffens, M.C. (2014), "How diversity training can change attitudes: Increasing perceived complexity of superordinate groups to improve intergroup relations", Journal of Experimental Social Psychology, Vol. 53 (July 2014), pp. 193-206.

Ely, R. (2004), "A field study of group diversity, participation in diversity education programs, and performance", Journal of Organizational Behaviour, Vol. 25 Issue 6, pp. 755-780.

Emerson, R. (1976), "Social exchange theory", Annual Review of Sociology, Vol. 2 (August 1976), pp. 335-362.

Evans, S. (2017), "HRM and front-line managers: the influence of role stress", The International Journal of HR Management, Vol. 28 Issue 22, pp. 3128-3148. 
Farh, J., Hackett, R. and Liang, J. (2007), "Individual-level cultural values as moderators of perceived organizational support-employee outcome relationships in China: Comparing the effects of power distance and traditionality", Academy of Management Journal, Vol. 50 No. 3, pp. 715-729.

Ferdman, B. and Brody, S. (1996), Models of diversity training, in Landis, D. and Bhagat, R.S. (Ed.), Handbook of intercultural training, Sage Publications, Thousand Oaks, pp. 282303.

Foster, C. and Harris, L. (2005), "Easy to say, difficult to do: DM in retail", $H R$ Management Journal, Vol. 15 No. 3, pp. 4-17.

Frese, M. and Fay, D. (2001), "Personal initiative: An active performance concept for work in the 21st century", in Staw, B.M. and Sutton, R.M. (Ed.), Research in Organizational Behavior, Elsevier Science, Amsterdam, pp. 133-187.

Gatenby, M., Rees, C., Truss, K., Alfes, K. and Soane, E. (2014), "Managing change, or changing managers? Challenging the role of line management in UK public services", Public Management Review, Vol. 17 Issue 8, pp. 1124-1145.

Gibb, S. (2011), HR Development: Process, Practices and Perspectives, $3^{\text {rd }}$ Edition., Palgrave Macmillan, Basingstoke.

Gigliotti, R., Vardaman, J., Marshall, D.R. and Gonzalez, K. (2018). "The Role of Perceived Organizational Support in Individual Change Readiness", Journal of Change Management, Vol. 19 Issue 2, pp. 86-100.

Glaser, B.G. and Strauss, A.L. (1967), The discovery of grounded theory: Strategies for qualitative research, Routledge, Taylor and Francis Group, London.

Glasman, R.L. and Albarracin, D. (2006), "Forming attitudes that predict future behaviour: a meta-analysis of the attitude -behaviour relation", Psychological Bulletin, Vol. 132 No. 5, pp. 778-822.

Gould-Williams, J. (2007), "HR practices, organizational climate and employee outcomes: evaluating social exchange relationships in local government", The International Journal of HR Management, Vol. 18 Issue 9, pp. 1627-1647.

Grace, C.B.H. (2013), "Absorptive capacity and characteristics of team who integrate knowledge for research in higher education", International Journal of Social and Behavioural Sciences, Vol. 1 No. 3, pp. 091-096.

Graen, G. and Scandura, T. (1987), "Towards a psychology of dyadic organizing", Research in Organizational Behavior, Vol. 9, pp. 175-208.

Greene, A. and Kirton, G. (2011), "DM meets downsizing: the case of a government department", Employee Relations, Vol. 33 No. 1, pp. 22-39.

Harney, B. and Jordan, C. (2008), "Unlocking the black box: Line managers and HRMperformance in a call centre context", International Journal of Productivity and Performance Management, Vol. 57 No. 4, pp. 275-296. 
Harris, K., Kacmar, K. and Zivnuska, S. (2007), "An investigation of abusive supervision as a predictor of performance and the meaning of work as a moderator of the relationship", The Leadership Quarterly, Vol. 18 Issue 3, pp. 252-263.

Hayles, R.V. (1996), "Diversity training and development", in Graig, R.L. (Ed.), The ASTD training and development handbook: A guide to HR Development, McGraw- Hill, New York, pp. 104-123.

Hayles, R.V. and Russell, A.M., (1997). "The diversity directive: Why some initiatives fail and what to do about it." New York, NY: ASTD. American Society for Training and Development.

Herdman, A.O. and McMIllan-Capehart, A. (2010), "Establishing a diversity program is not enough: Exploring the determinants of diversity climate", Journal of Business and Psychology, Vol. 25 No. 1, pp. 39-53.

Hunt, V., Layton, D. and Prince S. (2015), Why Diversity Matters, A report conducted for McKinsey \& Company (January 2015), Retrieved from McKinsey \& Company website, available at: https://www.mckinsey.com/business-functions/organization/ourinsights/why-diversity-matters [Accessed 20th August 2019].

Hutchinson, S. and Purcell, J. (2010), "Managing ward managers for roles in HRM in the NHS: Overworked and under-resourced", HR Management Journal, Vol. 20 Issue 4, pp. 357-374.

Jayne, M. and Dipboye, R. (2004), "Leveraging diversity to improve business performance: Research findings and recommendations for organizations", HRs Management, Vol. 43 Issue 4, pp. 409-424.

Kirkpatrick, D.L. and Kirkpatrick, J.D. (2006), "Evaluating training programs: The four levels", $3{ }^{\text {rd }}$ Edition, San Francisco, CA.

Köllen, T. (2019), "DM: A critical review and agenda for the future", Journal of Management Inquiry, August 2019, available online at doi: $\underline{10.1177 / 1056492619868025}$ [Accessed 17 ${ }^{\text {th }}$ September 2020].

Lin, H.F. and Lee, G.G. (2004), "Perceptions of senior managers toward knowledgesharing behaviour”, Management Decision, Vol. 42 No. 1, pp. 108-125.

Lincoln, Y. and Guba, E.G. (1985), Naturalistic inquiry. Sage Publications: Newbury Park, CA.

Lorbiecki, A. and Jack, G. (2000), "Critical Turns in the Evolution of DM", British Journal of Management, Vol. 11 Issue s1, pp. S17-S31.

Lune, H. and Berg, B.L. (2017), Qualitative research methods for the social sciences. Pearson: London.

Martins, L.P. (2015), "HR leaders hold the key to effective DM", HR Management International Digest, Vol. 23 No. 5, pp. 49-53.

Maxwell, G., Blair, S. and McDougall, M. (2001), "Edging towards managing diversity in Practice", Employee Relations, Vol. 23 No. 5, pp. 468-482. 
McClean, E. and Collins, C.J. (2011), "High-commitment HR practices, employee effort, and firm performance: investigating the effects of HR practices across employee groups within professional services firms”, HR Management, Vol. 50 Issue 3, pp. 341-363.

Miles, M.B. and Huberman, A.M. (1994), Qualitative data analysis: An expanded sourcebook, $2^{\text {nd }}$ edition, Sage Publications, London.

Ng, E.S. and Sears, G.J. (2020), Walking the talk on diversity: CEO beliefs, moral values, and the implementation of workplace diversity practices, Journal of Business Ethics, Vol. 164, pp. 437-450.

Ng, E.S., Sears, G.J. and Arnold, K.A. (2020), "Exploring the influence of CEO and chief diversity officers' relational demography on organizational DM: An identity-based perspective", Management Decision, Vol. ahead-of-print.

Nishii, L.H., Khattab, J., Shemla, M. and Paluch, R.M. (2018), “A multilevel process model for understanding diversity practice effectiveness". Academy of Management Annals, Vol. 12 No.1, pp. 37-82.

Nishii, L.H. and Mayer, D.M. (2009), "Do inclusive leaders help to reduce turnover in diverse groups? The moderating role of leader-member exchange in the diversity to turnover relationship", Journal of Applied Psychology, Vol. 94 No. 6, pp. 1412-1426.

Olsen, J.E. and Martins, L.L. (2012), "Understanding organizational DM programs: A theoretical framework and directions for future research", Journal of Organizational Behaviour, Vol. 33 Issue 8, pp. 1168-1187.

Op de Beeck, S., Wynen, J. and Hondeghem, A. (2015), "HRM Implementation by line managers: explaining the discrepancy in HR-line perceptions of HR devolution", The International Journal of HR Management, Vol. 27 Issue 17, pp. 1901-1919.

Paluck, E. (2006), "Diversity training and intergroup contact: A call to action research", Journal of Social Issues, Vol. 62 No. 3, pp. 577-595.

Purcell, J. and Hutchinson, S. (2007), "Front-line managers as agents in the HRMperformance causal chain: theory, analysis and evidence", HR Management Journal, Vol. 17 Issue 1, pp. 3-20.

Richard, O.C. (2000), "Racial diversity, business strategy and firm performance: A resource-based view", Academy of Management Journal, Vol. 43 No. 2, pp. 164-177.

Ryu, S. and Kim, S. (2013), "First-Line Managers' HR Involvement and HR Effectiveness: The Case of South Korea”, HR Management, Vol. 52 Issue 6, pp. 947-966.

Saunders, M., Lewis, P. and Thornhill, A. (2009), Research methods for business students. Pearson education: London.

Shapiro, D.L., Boss, A.D., Salas, S., Tangirala, S. and Von Glinow, M.A. (2011), "When are transgressing leaders punitively judged? An empirical test", Journal of Applied Psychology, Vol. 96 No. 2, pp. 412-422. 
Shen, L., Chanda, A., D’Netto, B. and Monga, M. (2009), "Managing diversity through HR management: an international perspective and conceptual framework", The International Journal of HR Management, Vol. 20 Issue 2, pp. 235-251.

Thompson, N. (1997), Anti-Discriminatory Practice, $2^{\text {nd }}$ Edition, Macmillan, Basingstoke.

Tomlinson, F. and Schwabenland, C. (2010), "Reconciling competing discourses of diversity? The UK non-profit sector between social justice and the business case", Organisation, Vol. 17 Issue 1, pp. 101-121.

Tufan, P, De Witte, K. and Wendt, H.J. (2019), "Diversity-related psychological contract breach and employee work behavior: insights from intergroup emotions theory", The International Journal of HR Management, Vol. 30 No. 20, pp. 2925-2949.

Ugaddan, R.G. and Park, S.M. (2017), "Quality of leadership and public service motivation: A social exchange perspective on employee engagement", International Journal of Public Sector Management, Vol. 30 Issue 3, pp. 270-285.

Van De Voorde, K., Paauwe, J. and Van Veldhoven, M. (2012), "Employee well-being and the HRM-organizational performance relationship: a review of quantitative studies", International Journal of Management Reviews, Vol. 14 Issue 4, pp. 391-407.

Vermeeren, B. (2014), "Variability in HRM implementation among line managers and its effect on performance: A 2-1-2 mediational multilevel approach", The International Journal of HR Management, Vol. 25 Issue 22, pp. 3039-3059.

Watson, S., Maxwell, G.A. and Farquhason, L. (2007), "Line Managers' Views on Adopting HR Roles: The Case of Hilton (UK) Hotels", Employee Relations, Vol. 29 No. 1, pp. 30-49.

Wright, P. and Nishii, L.H. (2013), "Strategic HRM and organizational behaviour: integrating multiple levels of analysis", in Paauwe, J., Guest, D. and Wright, P. (Ed.), HRM and Performance: Achievements and Challenges, Wiley, Chichester, pp. 97-110. 